\title{
CAPÍTULO 20: FORTALECIMENTO DA PEDAGOGIA DA ALTERNÂNCIA NA CASA FAMILIAR RURAL DE SÃO LUÍS - MA: ORIENTAÇÕES TÉCNICAS EM AVICULTURA CAIPIRA AOS EDUCANDOS
}

\section{CHAPTER 20: STRENGTHENING THE PEDAGOGY OF ALTERNANCE IN THE RURAL FAMILY HOUSE OF SÃO LUÍS - MA: TECHNICAL GUIDELINES FOR FREE-RANGE POULTRY FARMING FOR STUDENTS}

\author{
Erislayne Batalha dos Santos ${ }^{1}$; Victor Leite Bernardino ${ }^{2}$; Carlos Ferreira de Souza ${ }^{3}$; Nancyleni \\ Pinto Chaves Bezerra ${ }^{4}$; Danilo Cutrim Bezerra ${ }^{5}$
}

\section{Resumo}

A Pedagogia da Alternância é uma metodologia do ensino que conjuga diferentes experiências formativas tendo como finalidade a formação integral. Nesse contexto, objetivou-se contribuir para o fortalecimento da pedagogia da alternância na Casa Familiar Rural de São Luís - MA por meio de orientações técnicas em avicultura caipira à 17 jovens educandos. Para atingir o objetivo proposto, o estudo foi dividido em três etapas: (i) reunião com a direção da escola para apresentação pormenorizada do projeto; (ii) visitas técnicas à CFR-MA para identificação das demandas da escola, afim de diagnosticar a situação do processo formativo dos jovens educandos no que se refere à parte técnica/específica; e, (iii) assessoramento técnico dos jovens educandos e suas famílias para a produção racional das aves caipiras. Com os resultados desse trabalho fica evidente que o projeto está concatenado à metodologia pedagógica da escola. Foi possível perceber ganhos no ensino-aprendizagem dos alunos, por meio da articulação teoria e prática, estudo e trabalho, pontos norteadores da Pedagogia da Alternância. Como os estudantes são multiplicadores da informação espera-se que estes possam replicar as atividades racionais da avicultura caipira em propriedades rurais e na comunidade e contribuir com a geração de renda e transferência de tecnologia.

Palavras-chave: agricultura familiar, galinha caipira, educação do campo.

\begin{abstract}
Pedagogy of Alternation is a teaching methodology that combines different training experiences with the purpose of integral training. In this context, the objective was to contribute to the strengthening of the pedagogy of alternation in the Rural Family House of São Luís - MA through technical guidance in free-range poultry farming to 17 young students. To achieve the proposed objective, the study was divided into three stages: (i) meeting with the school management to present the project in detail; (ii) technical visits to the CFR-MA to identify the demands of the school, in order to diagnose the situation of the training process of young

\footnotetext{
${ }^{1}$ Curso de Zootecnia, Universidade Estadual do Maranhão, batalhaerislayne@ gmail.com

${ }^{2}$ Curso de Zootecnia, Universidade Estadual do Maranhão, leitevitor913@ gmail.com

${ }^{3}$ Curso de Zootecnia, Universidade Estadual do Maranhão, souzacarloszoo049@gmail.com

${ }^{4}$ Doutora em Biotecnologia, Universidade Estadual do Maranhão, nancylenichaves@ hotmail.com

5 Doutor em Biodiversiadde e Biotecnologia, Universidade Estadual do Maranhão, danilocbezerra15@gmail.com
} 
students with regard to the technical / specific part; and, (iii) technical advice to young students and their families for the rational production of free-range birds. With the results of this work, it is evident that the project is linked to the school's pedagogical methodology. It was possible to perceive gains in students' teaching-learning, through the articulation of theory and practice, study and work, guiding points of Pedagogy of Alternation. As students are multipliers of information, it is expected that they will be able to replicate the rational activities of free-range poultry farming in rural properties and in the community and contribute to the generation of income and technology transfer.

Keywords: family farming, free-range chicken, rural education.

\section{Introdução}

A Pedagogia da Alternância (PA) é uma proposta de educação rural voltada ao desenvolvimento integral do jovem do meio rural e tem, direta e indiretamente, reflexos na melhoria da qualidade de vida das famílias e na comunidade em que essas escolas estão inseridas, não se atendo apenas a temas rurais, mas também urbanos, garantindo na proposta a sua integralidade (GNOATTO et al., 2006).

A proposta da PA atende diferentes públicos, não somente agricultores familiares, já que o Campo não é lugar exclusivo desses, mas, também de filhos de outros trabalhadores que residem nesse espaço, trabalham, ganham a vida e tem a oportunidade de acessar essa proposta educativa-pedagógica (SOUZA; COSTA; VERGÜTZ, 2016).

$\mathrm{Na}$ PA o educando permanece um período em casa e outro na escola, ou seja, nas Casas Familiares Rurais (CFRs), com alternância de momentos em sua formação. Nessa proposta, a família/comunidade e a escola rompem com a ideia não construtiva que, ainda, permanece nos dias atuais e trata a escola como a principal responsável pela educação e desconsidera a família, a comunidade e as relações socioculturais estabelecidas no meio em que os alunos encontramse inseridos (COSTA, 2012).

A partir de uma visão que considera os jovens e o meio em que estão inseridos, a PA alcançou espaço e respaldo em outros países, sendo considerada uma referência metodológica preocupada com a formação integral dos educandos. De igual forma, as CFRs ocuparam espaço no Brasil e ampliaram sua atuação no território nacional.

A demanda premente por experiências como as CFRs no Maranhão ratifica a importância da agricultura familiar enquanto atividade econômica, notadamente em um Estado marcado historicamente pela agricultura não patronal, apesar das condições desfavoráveis que é essa perpassou e passa, entre elas, a perda de jovens para as cidades, por uma série de fatores. 
É na ampliação desse debate e na oferta de outras possibilidades aos jovens do campo, por meio da educação, que a gestão da CFR de São Luís - MA se debruça cotidianamente, mesmo com todas as dificuldades encontradas. O currículo nessa unidade de ensino básico contempla a formação geral e a específica: a primeira é constituída por disciplinas como português, arte, língua estrangeira, matemática, ciências, história, geografia, filosofia, religião e educação física; e a segunda, destinada à formação específica para o trabalho no meio rural, é composta pelas disciplinas de Zootecnia e Agricultura, onde são trabalhados diferentes assuntos (avicultura, caprino-ovinocultura, bovinocultura, suinocultura, fisiologia e reprodução animal entre outros).

Considerando a importância da PA, os gestores das CFR de São Luís - MA têm constantemente buscado parcerias para viabilizar a realização de suas atividades. Diante desse cenário, com vistas a atender as demandas foi executado por esta mesma equipe de trabalho no ano de 2018/2019 o projeto de extensão intitulado “AVICULTURA CAIPIRA: uma proposta da zootecnia para a Escola Casa Familiar Rural de São Luís - MA” cujo objetivo específico foi criar um lote de aves, como estação demonstrativa de avicultura caipira nessa instituição de ensino básico, e posterior doação à escola de forma que os educandos acompanhassem integralmente o ciclo produtivo das aves caipiras.

O projeto supracitado ganhou visibilidade por sua importância sócioeconômica e uma empresa multinacional doou para a CFR material para construção de aviários nas casas de alguns alunos, além dos pintainhos e ração. Porém uma lacuna desse projeto foi a não contemplação de assessoria técnica aos educandos e suas respectivas famílias para a garantia da sustentabilidade da atividade (avicultura caipira).

Nesse interim, destac-se que a avicultura caipira em pequenas propriedades é um sistema alternativo, que consiste em uma cultura dirigida ao agricultor familiar, capaz de organizar de forma gerenciada a atividade de criação destas aves. Esse sistema alternativo de criação pode melhorar a qualidade de vida das famílias, seja pela maior oferta de carne e ovos de qualidade na sua alimentação, ou pela possibilidade de venda do excedente, uma vez que aumenta de forma substancial e eficiente a capacidade produtiva do plantel (SOUZA JÚNIOR, 2011).

Embora seja reconhecida como uma fonte de alimentos de alta qualidade protéica (carne e ovos), e tenha se transformado ao longo dos tempos em um dos pratos típicos conhecidos em todo o território brasileiro, a forma de criação do frango caipira é precária em termos zootécnicos, com prejuízos para a sua produtividade, segundo Souza Júnior (2011). Desa forma, pela parceria já estabelecida entre a Universidade Estadual do Maranhão 
(UEMA/Curso de Zootecnia) e comunidade a partir da extensão universitária, bem como a importância dessa parceria para promover ações de Desenvolvimento Rural, é que se desenvolveu-se a presente pesquisa com o objetivo principal de contribuir para o fortalecimento da pedagogia da alternância na Escola Casa Familiar Rural de São Luís - MA por meio de orientações técnicas em avicultura caipira aos jovens educandos. E como objetivo secundário, melhorar a qualidade de vida das famílias que possam estar em situação de vulnerabilidade alimentar com o acesso à alimentação saudável e aumento da renda com a possibilidade de comercialização das aves caipiras.

\section{Material e Métodos}

\section{Local de estudo}

O estudo foi realizado com 17 jovens educandos da CFR de São Luís - MA contemplados com a construção de aviários e suas respectivas famílias. A referida escola apresenta modalidade de ensino de Educação de Jovens e Adultos - EJA/Ensino Fundamental. Está localizada no povoado de Santa Helena, Quebra-Pote, área rural do Município de São Luís - MA (Figura 1), no período de setembro de 2019 a março de 2020.

Figura 1. Escola Casa Familiar Rural de São Luís, estado do Maranhão

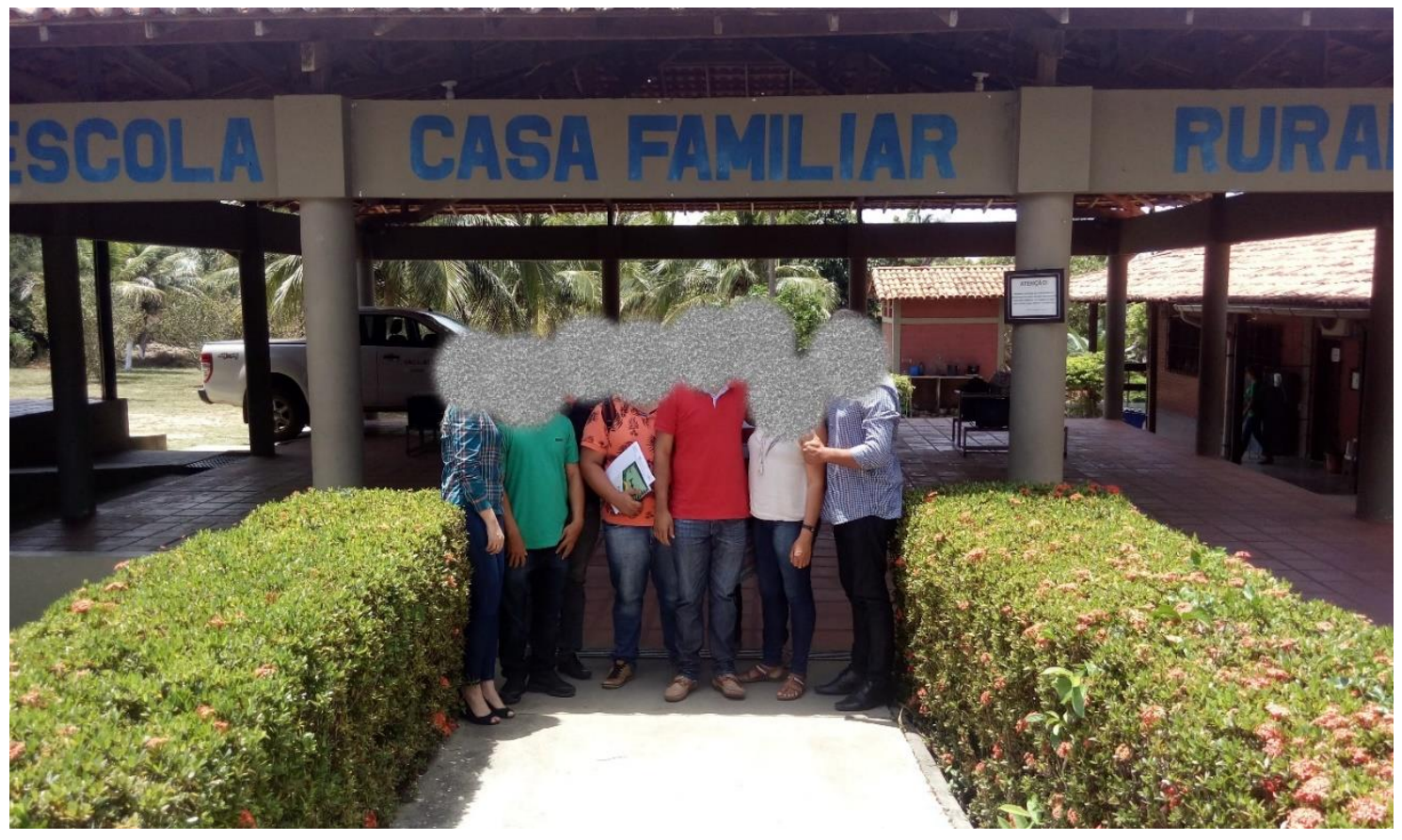

Fonte: Própria (2020). 
A CFR de São Luís - MA foi construída em uma parceria entre a Prefeitura Municipal de São Luís - MA e ALUMAR e, iniciou suas atividades no ano de 2001. A ECFR é mantida e administrada pela Secretaria Municipal de Educação (SEMED) da Prefeitura Municipal de São Luís. A escola possuia no período de execução da pesquisa 55 alunos, divididos em duas turmas. Estes são de classe média baixa, moradores de bairros periféricos e, principalmente da zona rural de São Luís - MA. A escola apresenta um quadro de seis professores, um técnico de nível superior e uma diretora. Ainda, um secretário, uma cozinheira e, dois funcionários responsáveis pelos serviços gerais da escola.

A estrutura física da ECFR é composta por uma sala de aula, uma sala de professores, uma secretaria, uma biblioteca, dois dormitórios, uma cozinha, banheiros, duas áreas livres, onde uma é denominada de quadra esportiva e a outra é a praça de recreação e, um campo para a execução das atividades de agropecuária, onde estão implantadas as unidades pedagógicas, como um aviário e três tanques escavados para a produção de peixes.

\section{Etapas do Estudo}

A primeira etapa do trabalho consistiu de uma reunião com a direção da escola (gestor, docentes e técnicos) para apresentação pormenorizada do projeto. A segunda etapa se efetivou por meio de visitas técnicas à CFR-MA para identificação das demandas da casa, afim de diagnosticar a situação do processo formativo dos jovens educandos no que se refere à parte técnica/específica. Já, na terceira etapa, foi realizada o assessoramento técnico dos jovens educandos e suas famílias para a produção racional das aves caipiras.

\section{Resultados e Discussão}

Para a implementação de qualquer atividade produtiva, esta deve ser submetida em sua fase inicial ao planejamento, seguido da orientação e assistência técnica. Em se tratando da avicultura caipira, a atividade demanda controle dos conceitos de sustentabilidade, sanidade e integração. Por isso, a importância desse estudo na oferta de assessoramento técnico às famílias com possibilidade de garantir a sustentabilidade das criações e sua reprodução ao longo do tempo.

No sentido de educar os estudantes a aprender de maneira autônoma e participativa, com o sentimento de partícipes do processo de construção do conhecimento, o presente projeto é uma importante ferramenta pedagógica no processo de ensino aprendizagem.

Os resultados desse trabalho são apresentados em conjunto por serem semelhantes entre os educandos. 


\section{a) Visitas Técnicas à Casa Familiar Rural de São Luís - MA}

Foram realizadas quatro visitas técnicas à CFR de São Luís - MA em que a primeira se pautou no planejamento das atividades (definição dos conteúdos a serem trabalhados, ferramentas pedagógicas utilizadas, carga horária e datas e quantidade de visitas às casas dos alunos).

Nesse momento do projeto, apesar de não ser objeto do estudo, houve uma conversa com a diretora da escola para uma melhor compreensão do perfil dos educandos da escola, que podem ser assim sumarizados: filhos de trabalhadores autônomos, agricultores rurais, empregadas domésticas, mães precoces, muitos dos pais não puderam frequentar os bancos escolares na idade prevista, pois, tinham que trabalhar para ajudar no orçamento familiar. E as famílias dos educandos procuram a escola na esperança de um futuro melhor aos seus filhos. Para eles, a escolarização significa a ampliação dos horizontes.

Mediante conversas e reuniões com diretor, professores, técnico e alunos houve a construção conjunta das atividades do presente projeto em congruência com o calendário das alternâncias e temas geradores ${ }^{4}$, resgatando a essência da Pedagogia da Alternância no enfoque da disciplina Zootecnia, módulo Avicultura.

Em função de atividades recentes sobre a avicultura caipira realizadas pela mesma equipe em um projeto anterior na mesma unidade de ensino, nas três visitas técnicas subsequentes, realizaram-se palestras educativas com os educandos contemplados e estas apresentaram um cunho eminentemente de revisão dos assuntos já trabalhados anteriormente, entre eles: manejo nutricional, sanitário e reprodutivo, boas práticas de fabricação, higiene e higienização no abate e preservação do meio ambiente.

Os conhecimentos teóricos foram transmitidos aos alunos por meio de aulas expositivas dialogadas com utilização de projetor multimídia, tipo data show. Nas palestras também foram utilizadas imagens e situações do cotidiano para dinamizar e contextualizar as capacitações. Nessa etapa do trabalho foram capacitados $100 \% \quad(n=17)$ dos alunos contemplados com material para construção de aviários em suas residências, além dos pintainhos e ração (Figura 2).

\footnotetext{
${ }^{4}$ Tema Gerador: tema ponto de partida para o processo de construção da descoberta que emerge das necessidades e anseios da comunidade. Estes devem ser extraídos da prática de vida dos educandos
} 
Figura 2. Jovens educandos da Casa Familiar Rural de São Luís - MA em capacitação teórica sobre avicultura

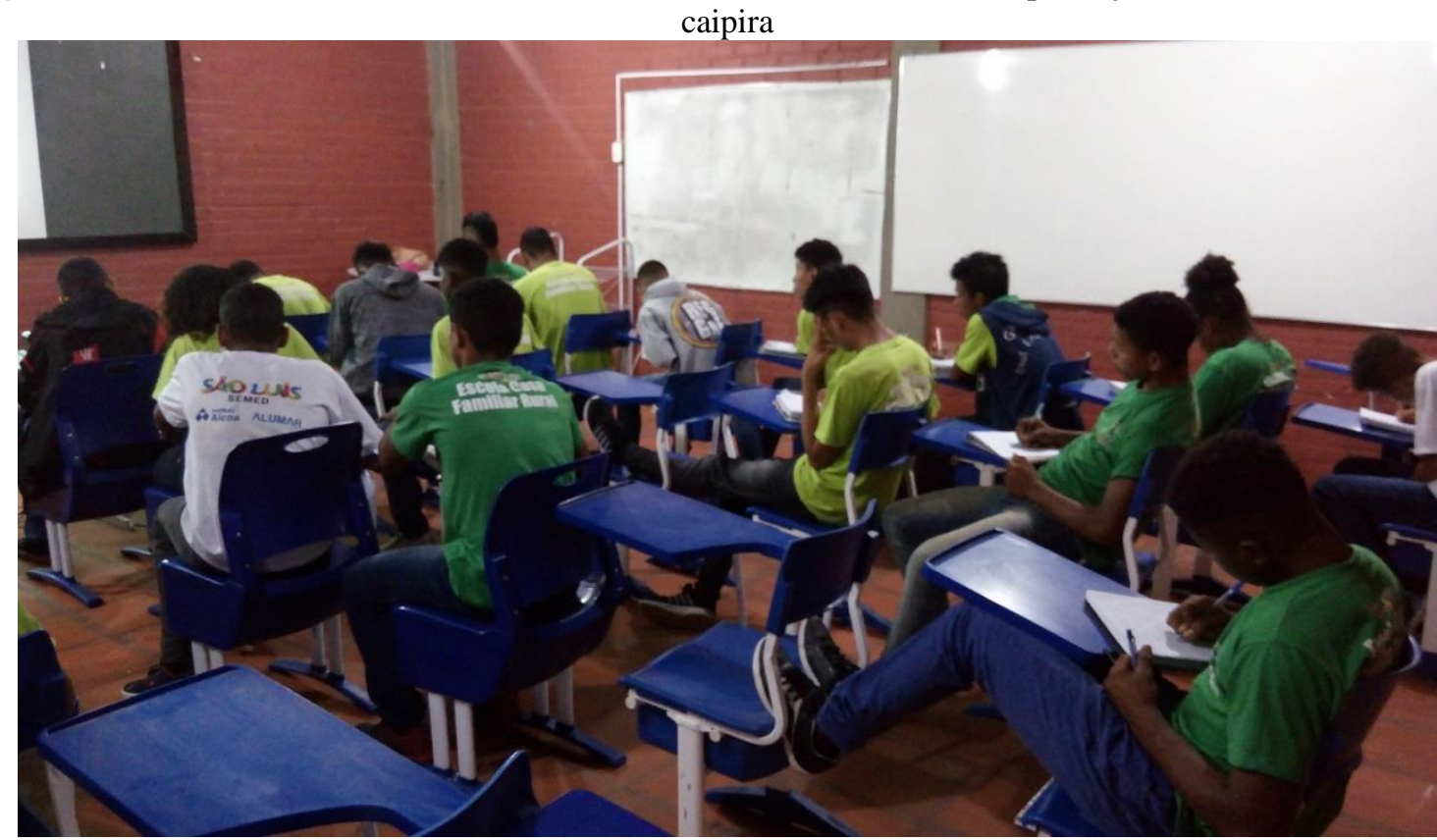

Fonte: Própria (2020).

Para Trajber e Mendonça (2007), dentre as funções mais relevantes das instituições educacionais está, sobretudo, seu potencial de transformação e influência em sua comunidade de abrangência. E é justamente por meio das temáticas voltadas para a educação sanitária, e nesse contexto a produção correta de alimentos, que a escola pode contribuir significativamente para a sociedade, criando canais de diálogo com a população, possibilitando discutir e refletir criticamente acerca do papel dos cidadãos.

Com o intuito de abordar a temática avicultura caipira utilizou-se as palestras como recurso didático. Esta de acordo com Behar, Passerino e Bernardi (2007) permite uma maior clareza na constituição da comunicação entre os participantes. Nesta perspectiva, abriram-se espaços discursivos em sala de aula, onde os estudantes puderam expressar seus pensamentos por meio da relação comunicativa entre aluno-aluno e aluno-professor como estrutura necessária para o fortalecimento do papel do professor como agente transformador e inovador no ambiente escolar e social.

Considera-se que as capacitações teóricas realizadas nesse momento do projeto se constituíram em um indicador, tanto quantitativo como qualitativo do projeto, pelo entendimento de que a educação é um processo ativo e contínuo capaz de educar e desenvolver consciência crítica no público-alvo. A educação sanitária é o processo de disseminação, construção e apropriação de conhecimentos, por parte dos participantes das diversas etapas das cadeias produtivas associadas às atividades agropecuárias e pela população em geral. Assim, o 
conhecimento das exigências de uma criação de aves caipiras de forma racional, por atividades educativas, pode reduzir a ocorrência de doenças, mortalidade, desperdício de ração e contribuir para uma matéria-prima de melhor qualidade.

\section{b) Assessoramento Técnico aos Jovens Educandos da Casa Familiar Rural de São Luís -} MA

Foram realizadas três (03) visitas técnicas com finalidade de assessoramento a cada um dos 17 educandos e suas famílias. A metodologia contemplou além dos treinamentos teóricos realizados em sala de aula previamente, explicações teórico-práticas sobre manejo para as famílias dos educandos, em suas próprias áreas, onde foram vistoriadas e analisadas as infraestruturas dos aviários, os tipos de animais pré-existentes (aves e outros), as vegetações naturais disponíveis (frutas, capim, arbustos, insetos) para o alimento alternativo destas aves, observando as normas sanitárias e os cuidados com a criação.

As referidas visitas tiveram a finalidade de identificar os principais entraves na produção avícola caipira local. Nessa etapa do trabalho de extensão (terceira etapa), também foram discutidos assuntos relativos ao manejo nutricional, sanitário e reprodutivo, boas práticas de fabricação, higiene e higienização no abate e preservação do meio ambiente. Os conhecimentos foram transmitidos por meio de conversa formal e atividades práticas in locu.

Na primeira visita técnica que aconteceu no momento de entrega dos 20 pintainhos às famílias, foi relatado por $100 \%$ das famílias alguma experiência de criação de aves domésticas (galinhas). Nesse momento, foi constatada na casa dos 12 educandos, a construção de aviários cobertos com disposição de comedouros e bebedouros. No espaço aberto, percebeu-se a existência de piquete para que as aves após 25 dias de alojamento pudessem ficar soltas para ciscar, buscar alimentos (como insetos e plantas), além de terem acesso à banho de sol. Contudo, para cinco jovens a estutura do aviário, equipamentos e utensílios não estavam completamente adequadas para o alojamento dos animais, sobretudo, no que se refere à não telagem das áreas laterais dos aviários, não colocação de comedouros e bebedourose presença de aves adultas nos aviários (Figura 3). 
Figura 3. Estrutura não conforme para alojamento de pintainhos na casa de um educando da Casa Familiar Rural

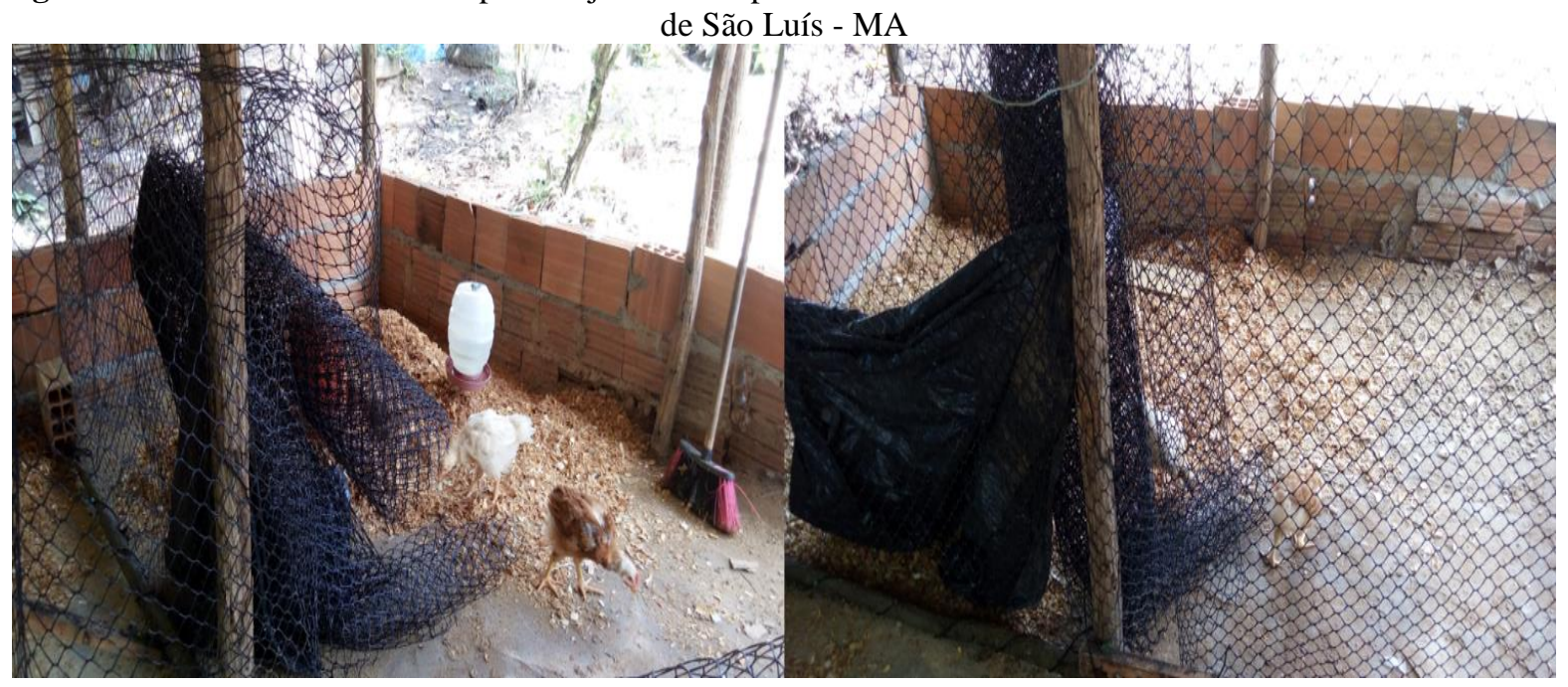

Fonte: Própria (2020).

Para esses alunos houve, nesse momento a improvisação de campânula, telas divisórias e círculo de proteção (Figura 4), além bebedouros e comedouros com materiais presentes na área. E, ocorreu intensificação na orientação técnica dessas famílias sobre a necessidade dos cuidados com essa fase da produção para o sucesso da criação.

Figura 4. Adequação de estrutura de aviário como materias para localidade para alojamento de pintainhos na casa de um educando da Casa Familiar Rural de São Luís - MA

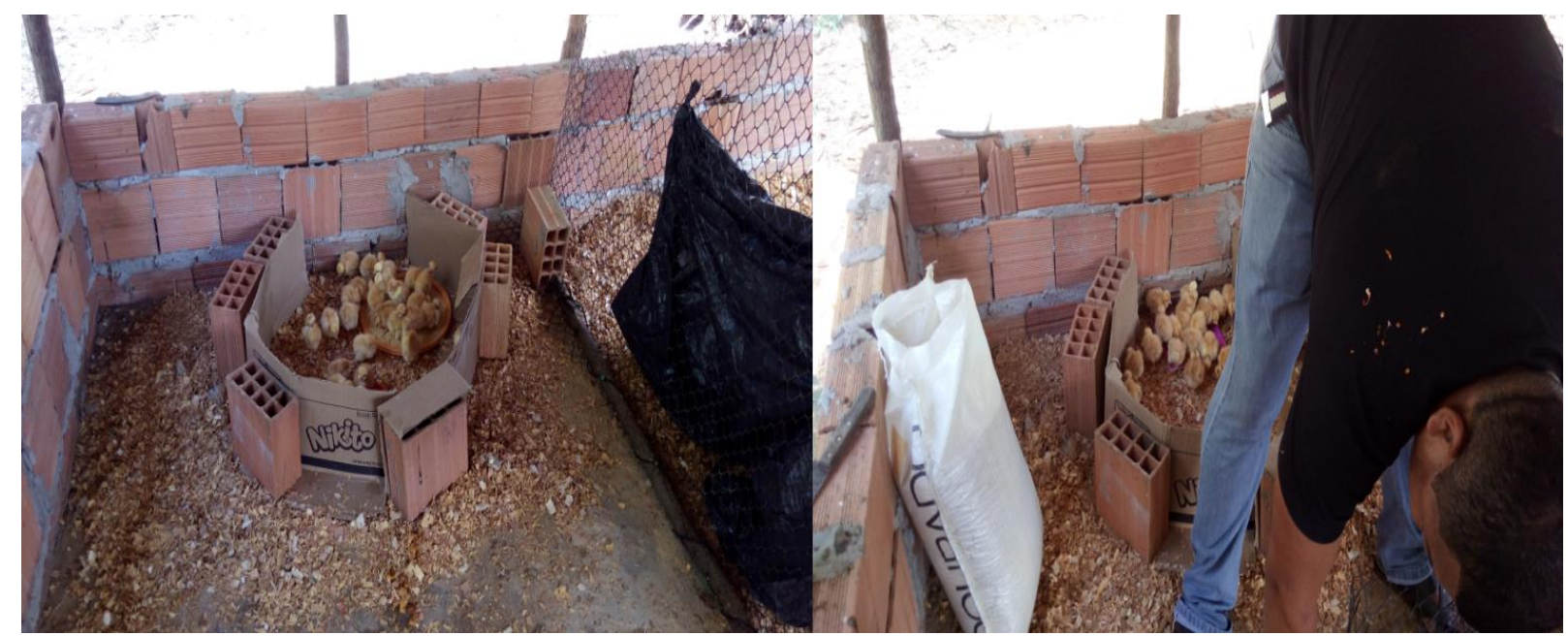

Fonte: Própria (2020).

Nas demais visitas técnicas que acompanharam as fases produtivas subsequentes não foram constatadadas inadequações no manejo executado por parte das famílias. Mediante os resultados alcançados foi viabilizado uma visita técnica com os alunos a um Instituto Federal de Educação, Ciência e Tecnologia para que os educandos pudessem compreender mais sobre os processo de produção de galinhas caipiras e a possibilidade da utilização de materias 
alternativos na criação (Figura 5).

Figura 5. Visita técnica com os alunos da Casa Familiar Rural de São Luís - MA ao Instituto Federal de Educação, Ciência e Tecnologia para maior compreensão da avicultura capira.

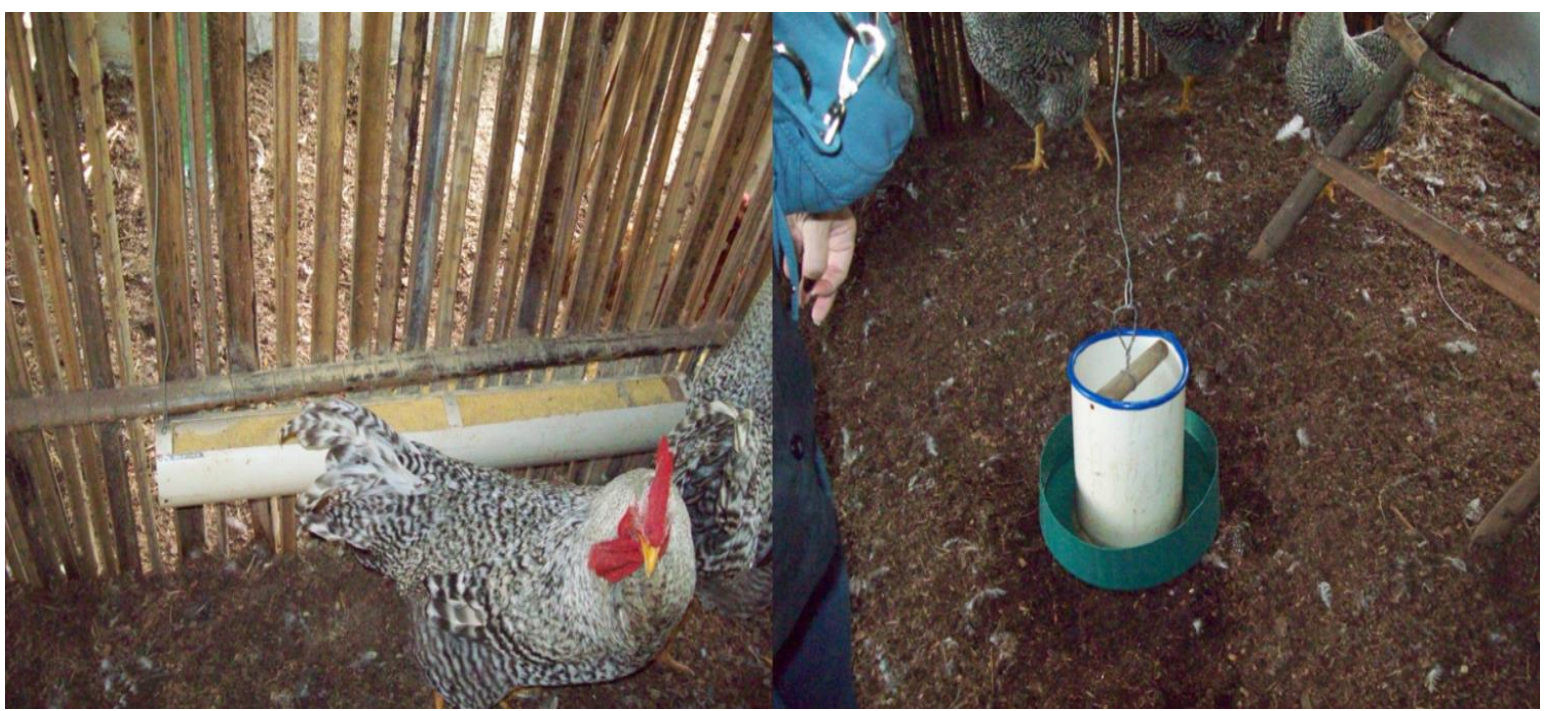

Fonte: Própria (2020).

Para Cruz, Chagas e Botelho (2013), a avicultura familiar apresenta as seguintes vantagens: a) utilização de terras fracas e desvalorizadas, na implantação da atividade; b) baixo investimento em instalações e equipamentos; c) melhoria da qualidade da dieta do produtor e sua família através do incremento protéico; d) fixação do produtor na propriedade; e) asseguramento de renda complementar ao orçamento familiar. Como desvantagens: a) necessidade de maior área para a implantação do sistema de produção; b) crescimento lento e produção de ovos das linhagens de aves inferior ao sistema industrial (convencional); c) maior exposição das aves a possíveis agentes patogênicos.

Especficamente a última informação do parágrafo supracitado, um ponto importante a ser destacado neste projeto, está em consonância com as exigências sanitárias que o Ministério da Agricultura, Pecuária e Abastecimento (MAPA) disciplina, pois no Brasil, por suas características próprias, é difícil controlar a criação de aves caipiras que ficam totalmente soltas. Desta forma, neste projeto foi apresentada uma forma controlada de criação, despetando nos alunos e suas famílias mudanças no manejo, não deixando de existir uma criação rústica, porém, com orientação sanitária correta, contribuindo com a melhoria na saúde animal, assim como nq seguranças dos alimentos produzidos.

Nesse enfoque foi realizada, também, uma oficina prática na casa de um dos educandos com alcance aos demais alunos sobre a aplicação de medicamentos e vacinas nas aves (Figura $6)$. 
Figura 6. Jovens educandos da Casa Familiar Rural de São Luís - MA em oficina prática sobre vias de aplicação de medicamentos e vacinas em aves.

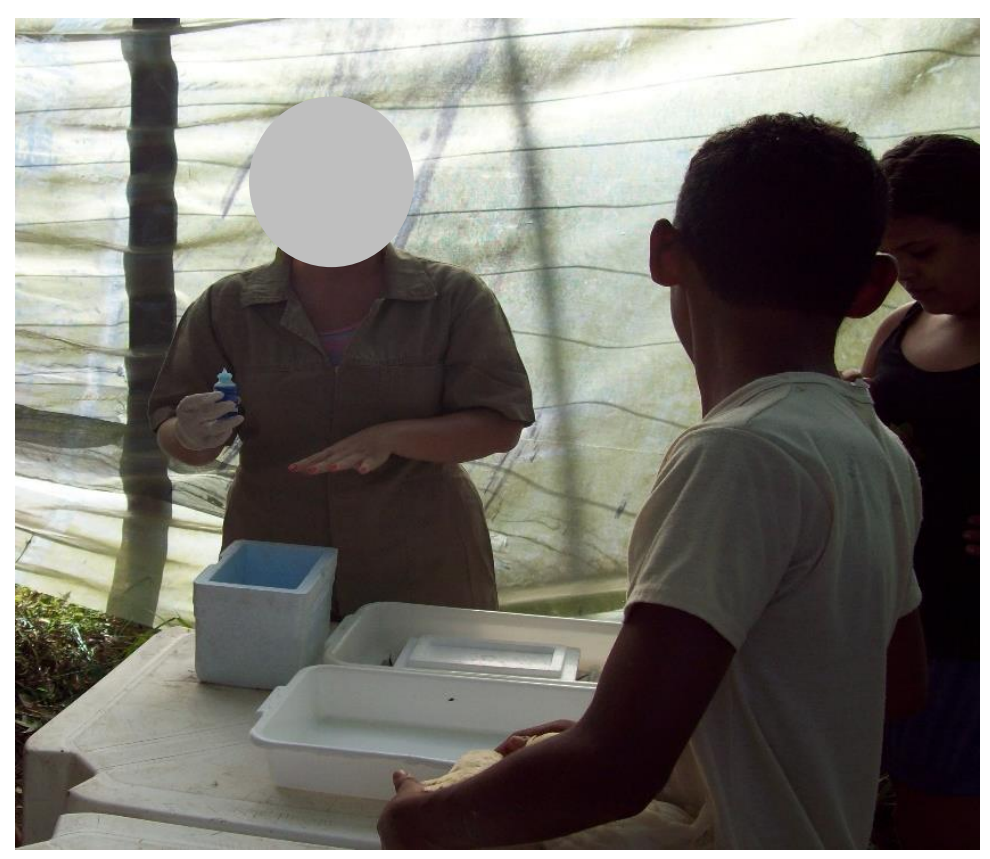

Fonte: Própria (2020).

A criação caipira de galinhas em comunidades pequenas não possui a intenção de competir com a avicultura industrial, mas representa um grande potencial como componente para estruturar o desenvolvimento local, conforme destacado por Fraxe et al. (2007), além de preencher um nicho de mercado com produtos originados de um sistema alternativo de produção e com isso atender aos consumidores com uma alimentação mais natural, de acordo com Cruz (2011).

Ao final deste trabalho, os educandos possuíam uma média de $925 \%$ de aves vivas. Quanto às atividades de manejo, a atuação dos educando e seus familiaresem relação ao proposto no projeto, foi adequada. Dessa forma, o mesmo alcançou o objetivo previamente estabelecido com consequentemente aumento no incremento protéico na alimentação das famílias e possibilidades de geração de fonte alternativa de renda com a venda de alguns animais.

\section{Conclusões}

A Pedagogia da Alternância é uma proposta educacional para os agricultores e seus filhos. Essa tem por objetivo o desenvolvimento de um ensino adaptado às realidades dos jovens, profissionalizando-os, tendo como premissa a construção do conhecimento em conjunto: escola, família e jovens, sujeitos de seu próprio desenvolvimento. 
Fica evidente, que a pesquisa realizada está concatenado à metodologia pedagógica da Casa Familiar Rural de São Luís - MA. Diante dos resultados obtidos foi perceptível ganhos no ensino-aprendizagem dos alunos, por meio da articulação teoria e prática, estudo e trabalho, pontos norteadores da Pedagogia da Alternância.

Não há dúvida que assessoramento técnico os educandos poderão ter potencial para serem empreendedores nas redes de produção, atuando em favor do desenvolvimento do meio rural. Como os estudantes são multiplicadores da informação espera-se que estes possam continuar a replicação da produção de aves caipiras em suas áreas rurais e na comunidade e contribuir com a geração de renda e transferência de tecnologia.

\section{Referências}

BEHAR, P. A.; PASSERINO, L.; BERNARDI, M. Modelos Pedagógicos para Educação a Distância: pressupostos teóricos para a construção de objetos de aprendizagem. In: Revista Novas Tecnologias na Educação, Rio Grande do Sul, v. 5, n. 2, p.1-12, 2007.

CRUZ, F. G. G.; CHAGAS, E. O DAS; BOTELHO, T. R. P. Avicultura familiar como alternativa de desenvolvimento sustentável em comunidades ribeirinhas do Amazonas. INTERAÇÕES, Campo Grande, v. 14, n. 2, p. 197-202, jul./dez. 2013.

COSTA, J. P. R. Escola família agrícola de Santa Cruz do Sul - EFASC: uma contribuição ao desenvolvimento da região do Vale do Rio Pardo a partir da pedagogia da alternância. 2012. 226f. Dissertaçã (Mestrado em Desenvolvimento Regional) - Universidade de Santa Cruz do Sul, Santa Cruz do Sul, 2012.

CRUZ, F.G.G. Avicultura caipira na Amazônia. Manaus: Grafi sa, 2011. 114p.

FRAXE, T. J. P. et al. Comunidades ribeirinhas amazônicas: modos de vida e uso dos recursos naturais. Manaus: EDUA, 2007. 223p.

GNOATtO, A. A.; RAMOS, C. E. P.; PIACESKI, E. E.; BERNARTT, M. de L. Pedagogia da alternância: uma proposta de educação e desenvolvimento no campo. In: XLIV CONGRESSO DA SOBER “Questões Agrárias, Educação no Campo e Desenvolvimento”, 2006, Fortaleza. 
SOUZA, M. B. DE; COSTA, J. P. R.; VERGÜTZ, C. L. B. A pedagogia da alternância e o ensino de história: o caso da escola família agrícola de Santa Cruz do Sul. Ágora, v.17,n. 02, p. 53-67, 2016.

SOUZA JÚNIOR, D. I. de. Criação de frango caipira visando a produção orgânica em pequenas propriedades no município de Bocaiúva do Sul - PR. 2011. 68 p. Monografia (Trabalho de Conclusão de Curso) - Universidade Tuiuti do Paraná, Paraná, 2011.

TRAJBER, R.; MEDONÇA, P. R. Educação na diversidade: o que fazem as escolas que dizem que fazem educação ambiental. Brasília: Secretaria de Educação Continuada, Alfabetização e Diversidade, 2007. 262 p. 